\section{The energetic British}

\author{
Peter C. Hinkle
}

Bacterial Energy Transduction. Edited by Christopher Anthony. Academic: 1988. Pp. 517. \$98, 147.

BACTERIA have found a remarkable number of ways to make a living. Indeed, the information about alternative pathways for oxidative, photosynthetic and transport reactions is so vast that few try to master it all.

To facilitate teaching in this area nine British biochemists have contributed to this advanced text, and have succeeded in providing both introductory parts and well-coordinated reviews that will be very useful, both for students and researchers. The emphasis is on electron-transfer chains. There are two chapters on the relatively new field of periplasmic electron transport, as well as thorough coverage of anaerobic, chemolithotrophic, oxidative and photosynthetic electron transport.

The work is dedicated to Peter Mitchell, and the mechanisms of energy transduction are analysed in terms of Mitchell's chemiosmotic theory. The last chapter, by a chemiosmotic heretic, tries to undermine the general acceptance of that theory, but does not succeed. Presumably, the editor thought it would be healthy for students to be exposed to what remains of the once strong opposition to chemiosmosis, because he instructed the author to end with the statement that "we should not believe all that we read (including this chapter)".

The main weakness of the book is the limitation to British authors, which has caused some important topics to be left out and others to be covered with less enthusiasm than original researchers would have provided. There is no coverage of chemotaxis and the flagellar rotor, an advanced field that is certainly one of the most interesting aspects of bacterial energy transduction. The recent determination of the crystal structure of photosynthetic reaction centres is reviewed in its relation to electron transfer, but the actual structure of the protein is not presented. Bacteriorhodopsin is barely mentioned. The extensive sequence information on bacterial transport proteins is poorly covered and the techniques of molecular biology, which are central to recent advances in the field, are largely ignored. Perhaps those of us in the rest of the world should consider writing a second, companion volume to fill in the gaps.

Peter C. Hinkle is in the Section of Biochemistry, Molecular and Cell Biology, Biotechnology Building, Cornell University, Ithaca, New York 14853, USA.

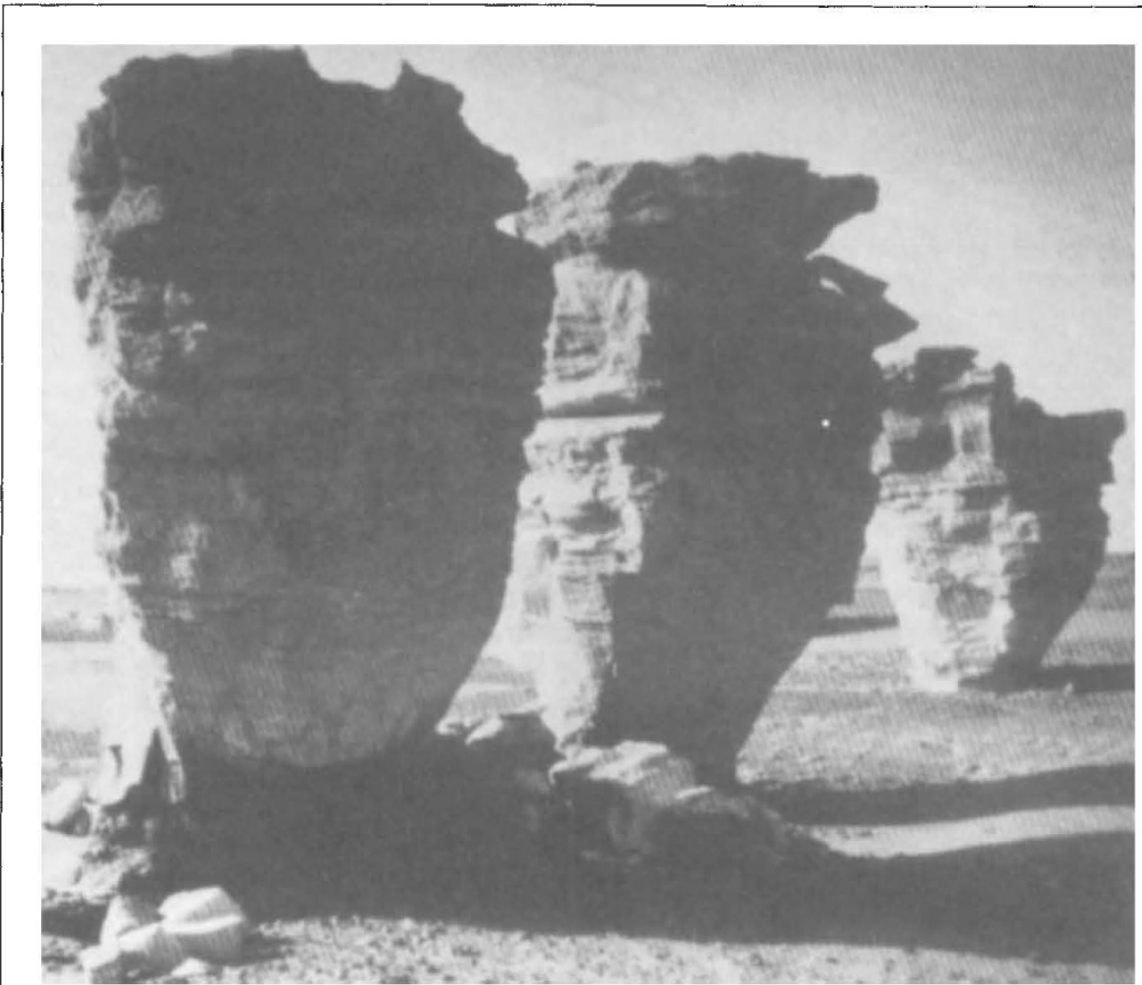

At the bottom of a lake - early Holocene lake sediments from Taoudenni in the central Sahara, subsequently eroded by the wind to form pillars. The picture is taken from the Holocene: An Environmental History by Neil Roberts, published by Basil Blackwell.

\section{Frameworking}

\section{V. C. Rees}

Molecular Sieves: Principles of Synthesis and Identification. By R. Szostak. Van Nostrand Reinhold: $1989 . \quad$ Pp.524. $£ 53.95, \$ 75.95$.

An Introduction to Zeolite Molecular Sleves. By Alan Dyer. Wiley: 1988. Pp.149. £29.50, \$64.95.

Although synthesis of zeolites was an important component in the growth of research on these materials during the 1960 s and 1970s, it was not until 1982, and the appearance of Barrer's Hydrothermal Chemistry of Zeolites, that the topic was covered by a monograph. The book dealt with many different aspects of the synthesis reaction from a more academic point of view, and helped greatly in putting the subject onto a firm scientific footing. Five years later, Jacobs and Martens published Synthesis of High-Silica Aluminosilicate Zeolites, a timely volume which contained a number of selected, proven recipes for high-silica zeolites, as well as detailed discussions of the synthesis of a number of different groups of such zeolites.

Now we have Rosemarie Szostak's Molecular Sieves. Szostak deals with the basic principles of synthesis, as did Barrer, but she puts greater emphasis on the practical aspects of the subject and is more concerned with methods of characterizing the products. Also included is a large section on non-aluminosilicate molecular sieves, which contains many examples of zeolites where the framework aluminium has been partly or completely replaced by a number of other elements. This section, which complements the material covered in Jacobs and Martens, also contains a broad and important survey of aluminophosphate, silicoaluminophosphate and metalloaluminophosphate molecular sieves.

I received Molecular Sieves just before departing on a three-week visit to the National Chemical Laboratory in Puna, India. The laboratory has a large group working on the synthesis of many of the materials discussed by Szostak. The value of her book is exemplified by the fact that it was in continuous demand by all members of the group - I saw little of it during my stay.

Alan Dyer, author of the second volume reviewed here, has been involved with zeolites for over 30 years, and is thus well qualified on the subject. His is an introductory account, and in the space of only 145 pages he describes clearly most aspects of the properties and uses of zeolites, both natural and synthetic. This book will be essential reading for any undergraduate encountering zeolites and molecular sieves for the first time, and for chemists who wish to acquire a basic knowledge of these materials.

L. V. C. Rees is a Professor in the Department of Chemistry, Imperial College, London SW7 $2 A Y, U K$. 